\title{
Iatrogenic Lesions of the Ureter Following Obstetric or Gynaecological Surgery Managed at Yalgado Ouedraogo University Hospital: A Series of 14 Cases
}

\author{
Timongo Françoise Danielle Millogo/Traore ${ }^{1 *}$, Kiswendsida Bonkoungou ${ }^{1}$, \\ Fasnéwindé Aristide Kabore ${ }^{2}$, Ali Ouedraogo ${ }^{1}$, Léonie Claudine Lougue/Sorgho ${ }^{3}$ \\ ${ }^{1}$ Department of Obstetrics and Gynaecology, Yalgado Ouédraogo University Hospital, Ouagadougou, Burkina Faso \\ ${ }^{2}$ Department of Urology and Andrology, Yalgado Ouédraogo University Hospital, Ouagadougou, Burkina Faso \\ ${ }^{3}$ Department of Radiology and Imaging, Charles de Gaulle University Hospital, Ouagadougou, Burkina Faso \\ Email: ^fmillogo_traore@yahoo.fr
}

How to cite this paper: Millogo/Traore, T.F.D., Bonkoungou, K., Kabore, F.A., Ouedraogo, A. and Lougue/Sorgho, L.C. (2018) Iatrogenic Lesions of the Ureter Following Obstetric or Gynaecological Surgery Managed at Yalgado Ouedraogo University Hospital: A Series of 14 Cases. Open Journal of Obstetrics and Gynecology, 8, 106-112.

https://doi.org/10.4236/ojog.2018.82014

Received: December 15, 2017

Accepted: February 5, 2018

Published: February 8, 2018

Copyright $\odot 2018$ by authors and Scientific Research Publishing Inc. This work is licensed under the Creative Commons Attribution International License (CC BY 4.0).

http://creativecommons.org/licenses/by/4.0/

\section{(c) (i) Open Access}

\begin{abstract}
Objective: To describe the aetiology, clinical presentation, management and outcomes of a series of patients with iatrogenic lesions of the ureter following obstetric or gynaecological surgery treated at Yalgado Ouedraogo University Hospital, Ouagadougou, Burkina Faso. Methods: This is a case series looking at 14 consecutive patients from 1 January 2011 to 28 February 2017, operated on for urological complications following obstetric and gynaecological surgery. Results: Our study focused on fourteen cases. The average age was 32.9 years (range 20 - 60 years). Thirteen were housewives. Eleven lived in rural areas. The aetiological factor was Caesarian section in seven cases, laparotomy in four cases and hysterectomy in three cases. The type of ureteral injury was bilateral ligation in nine cases. The average time to diagnosis was 16 days (range 2 - 120 days). Anuria was the commonest presenting symptom. Ultrasound in ten patients showed evidence of uretero-hydronephrosis. Eight patients required renal dialysis. Surgical management was uretero-vesical reimplantation in eleven cases, disunion of sutures associated with catheterization in two cases and a termino-terminal ureteral anastomosis in one case. The average hospital stay was 26 days (range 9 - 44 days). The post-operative period was complicated by two cases of vesico-vaginal fistula, one case of parietal suppuration, one case of pyelonephritis and one case of hydronephrosis. No deaths were recorded and a complete cure was ultimately obtained in all patients. Conclusion: Urological complications of obstetric and gynaecological surgery are dominated by ligation of the ureters in our setting. Caesarian section is the commonest cause. Treatment is essentially surgical.
\end{abstract}




\section{Keywords}

Iatrogenic Lesion, Ureter, Obstetric and Gynaecological Surgery

\section{Introduction}

Iatrogenic lesions of the ureter are rare $(0.1 \%$ to $1.5 \%)$ but serious complications of various surgical interventions involving the abdomen, pelvis or even the spine [1] [2]. Gynaecological, urological, gastrointestinal and vascular surgeries respectively make up about 50\%, 35\%, 15\%, and 5\% of these lesions [3]. Gynaecological surgery seems most exposed to the risk of ureteral injury with some studies reporting frequencies of $50 \%$ to $70 \%$ of iatrogenic lesions in the course of these procedures [4] [5] [6]. The location of the ureter near the internal female reproductive organs especially at the level of its pelvic segment explains this frequency [4] [7]. However, these lesions can occur during gastrointestinal surgery, particularly during abdominoperineal resection (5\% - 15\%) or during vascular surgery [3]. Mechanisms of injury are either direct by resection or canal obstruction, or indirect by devascularization and secondary ureteral necrosis [3]. Delayed diagnosis can cause significant morbidity [8], therefore early diagnosis and timely surgical management is justified. The objective of our work was to study the aetiology, clinical features, management and outcomes of iatrogenic lesions of the ureter following obstetric or gynaecological surgery treated at Yalgado Ouedraogo University Hospital.

\section{Methods}

It was a case series study of patients treated at the Department of Urology and Andrology, Yalgado Ouedraogo University Hospital for iatrogenic lesions of the ureter following obstetric or gynaecological surgery collected from 1 January 2011 to 28 February 2017. It was a retrospective study that was directed by the Department of Obstetricsand Gynaecology in collaboration with the Department of Urology and Andrology of Yalgado Ouedraogo University Hospital. Allthe patients treated at the Department of Urology and Andrology of Yalgado Ouedraogo University Hospital at that period was included in the study. We found fourteen patients. Data were collected from clinical records, supplementary investigations as well as operative records. The variables studied were: age, occupation, place of residence, mode of reference, aetiology of ureteral injury, place of obstetric or gynaecological surgery, operator qualification, time taking to consult, clinical features, surgical management, diagnosis, days of hospitalization, outcome and mortality. The data was analyzed with SPHINX Software.

\section{Results}

Our study focused on fourteen cases. The average age was 32.9 years (range 20 60 years). Thirteen patients were housewives and one was a public servant. Ele- 
ven of the fourteen patients lived in rural areas. Anuria was the presenting symptom in nine cases. The main aetiologies found were Caesarean section in seven cases, laparotomy for uterine rupture in four cases and hysterectomy in three cases. The initial surgical procedure was performed in a peripheral medical center in nine cases. In half of cases the operator was a general practitioner trained in emergency surgery. The average time to diagnosis was 16 days (range 2 - 120 days).

The main manifestations of iatrogenic lesions of the ureter are shown in Figure 1.

The abdominal and pelvic ultrasonography performed in ten patients showed evidence of uretro-hydronephrosis. The intravenous urography carried out in one case showed evidence of left uretero-nephrosis. Renal function was normal in four patients whilst ten showed evidence of renal failure with serum creatinine ranging from 579 to $1772.7 \mu \mathrm{mol} / \mathrm{L}$. Surgical management consisted of uretero vesical re-implantation in eleven cases with eight repaired using the Politano-Leadbetter technique, one with Paquin's procedure, one by the Lich Gregoir technique and one with psoas bladder hitch. Other surgical management was disunion of sutures associated with catheterization in two cases and a termino-terminal ureteral anastomosis in one case. Bilateral ligation of the ureters was the intraoperative diagnosis found in nine cases (Table 1).

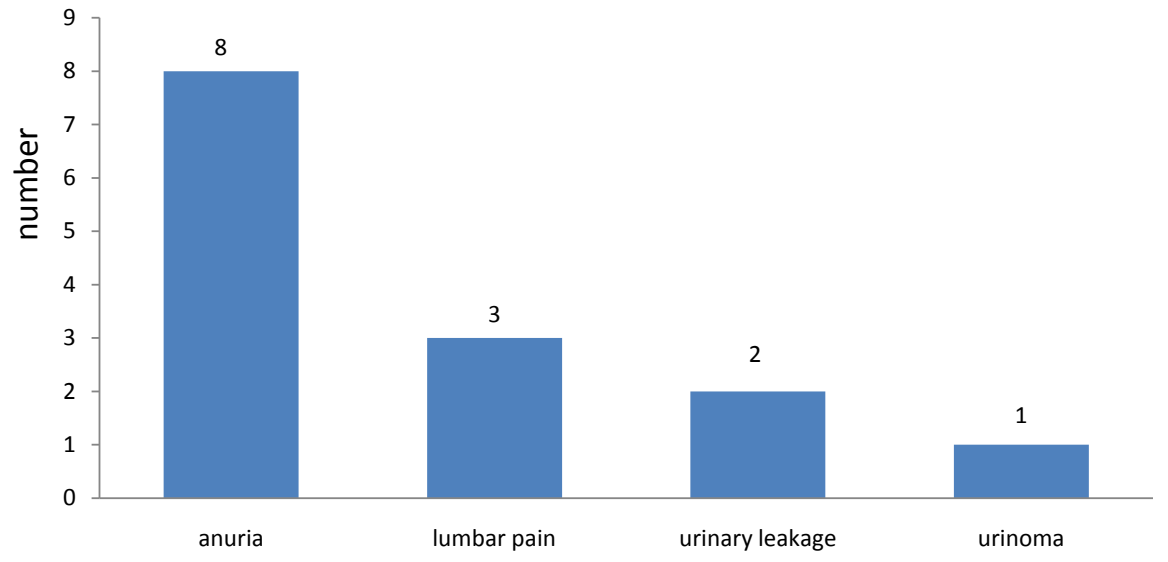

Figure 1. Distribution of patients according to the main manifestations of iatrogenic lesions of the ureter.

Table 1. Distribution of patients according to the type of lesion.

\begin{tabular}{cc}
\hline Type of lesion & Number of patients \\
\hline Bilateral ligation of the ureter & 09 \\
Uretero-vaginal fistula & 01 \\
Partial resection of the right ureter & 01 \\
Left ureteral resection & 01 \\
Unilateral ligation with shredding & 01 \\
bilateral Ligation and resection of the ureter & 01 \\
\hline
\end{tabular}


The mean duration of hospitalization for patients was 26 days (range 9 - 44 days).

The early post-operative period was uncomplicated in all patients but there were late complications of vesico-vaginal fistula in two cases, one case of parietal suppuration, one case of pyelonephritis and one case of hydronephrosis. No deaths were recorded and a complete cure was ultimately obtained in all patients.

\section{Discussion}

The patients in our study were predominantly young, with an average age of 32.9 years (range 20 - 60 years). Our results are similar to those reported by Diallo $\mathrm{AB}$ et al. in Guinea Conakry who reported an average age of 31 years (range 18 47 years) [9]. On the other hand, they differ from those of Rafique $M$ in Pakistan [10], Chalya P et al. in Tanzania [11], Bouya PA et al. in Congo [12] and Traoré $\mathrm{Y}$ et al. in Burkina Faso [13] who respectively found an average age of 35, 36, 37 and 38.5 years. All these studies show that iatrogenic lesions of the ureter usually occur in young women of childbearing age. Caesarian section with seven cases and laparotomy for uterine rupture in four cases were the leading causes of the iatrogenic lesions of the ureter in our study. Bouya et al. in 2011 in Congo found Caesarian section as main aetiology of iatrogenic lesions of the ureter in 50\% [12] while Hounnasso PP et al. in 2014 in Benin noted 53.7\% of cases [14]. Our results are similar to Diallo AB in Guinea Conakry who found in 2015 that $74.36 \%$ of iatrogenic lesions of the ureters were attributable to Caesarian section [9]. Caesarian section is the most common surgical procedure resulting in iatrogenic lesions of the ureters. Many of these procedures were performed by general practitioners trained in emergency surgery. Indeed, these operator profiles were involved in the onset of iatrogenic lesions of the ureter in half of the cases in our study. This could be explained by the fact that eleven out of fourteen of our patients resided in rural areas and nine out of fourteen procedures were performed in a peripheral medical centre. This result corroborates the data reported by Hounnasso P.P et al. in Benin [14] who noted that $73.2 \%$ of the patients in their series were operated at peripheral health structures before their transfer to Cotonou University Hospital. Chalya P in his study in Tanzania, observed the same in $93.9 \%$ of cases [11]. The average time to diagnosis was 16 days (range 2 - 120 days). Our results are similar to those of Chalya $\mathrm{P}$ which found an average delay of $14 \pm 2$ days (range 02 - 172 days) [11] and of Karmouni who noted an average delay of 13 days (range 00 - 60 days) [3]. Anuria was the main presenting symptom in our series. This result corroborates that of Benchekroun who found thirty-three cases of anuria out of forty-two [15]. Ultrasound and intravenous urography were performed in ten of the fourteen patients and had demonstrated evidence of uretero-hydronephrosis. Our results corroborate those obtained by Benchekroun [15], Chalya [11], Hounnasso [14] and Karmouni [3]. Renal insufficiency was noted in ten (71.4\%) patients. This 
result is similar to Diallo in Guinea, who found elevated creatinine in $72.2 \%$ of patients with iatrogenic lesions of the ureter [9]. In nine out of fourteen cases bilateral ligation of the ureters was found. Chalya $\mathrm{P}$ in his study found that ureteral ligation accounted for $36.6 \%$ of ureteral lesions [11]. Surgical treatment consisted of uretero-vesical reimplantation in eleven patients; suture disunion associated with ureteral catheterization in two patients and termino-terminal ureteral anastomosis in one patient. Uretero-neocystostomy or uretero-vesical reimplantation was the most common reconstructive surgery in $58.0 \%$ of patients in the Chalya study in Tanzania [11]. For Hounnasso in Benin, surgical treatment consisted of unilateral ureteral reimplantation in four cases, elimination of ureteral ligation in three cases, bilateral ureteral reimplantation for two cases and termino-terminal anastomosis in one case [14]. The average length of stay at hospital in our study was 26 days (range 9 - 44 days). Chalya in Tanzania had an average duration of 12 days (range 1 - 75 days) [11]. We noted complications as vesico-vaginal fistula in two cases, one case of parietal suppuration, one case of pyelonephritis and one case of hydronephrosis. Diallo reported two (02) cases of vesico-vaginal fistula, three cases of parietal suppuration and one case of vesico-cutaneous fistula [9] (Figures 2-4).

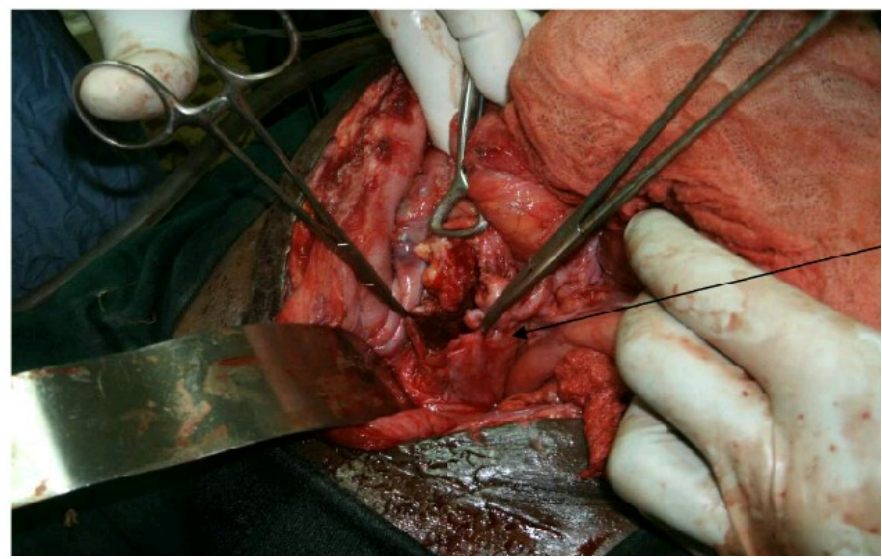

Figure 2. Dissection of a mega-ureter accidentally ligated during a hysterectomy (Source Urology/Yalgado Ouédraogo University Hospital).

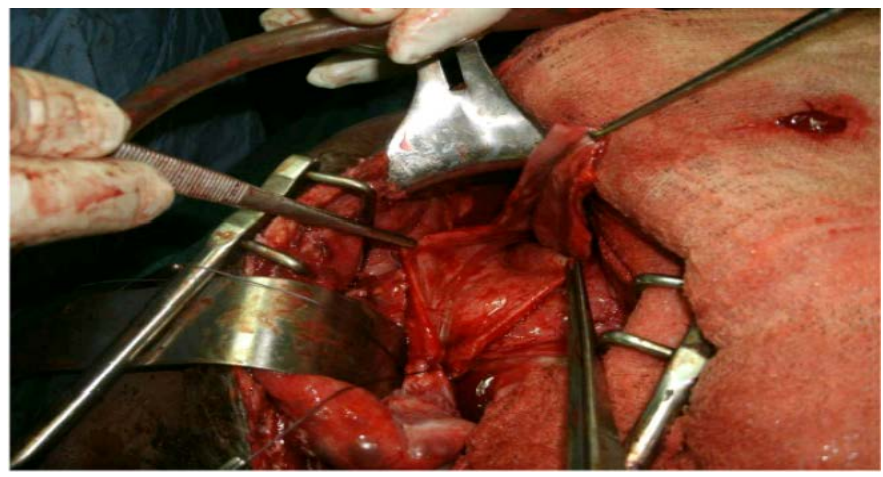

Figure 3. Dissection and catheterization of the ureter (Source Urology/ Yalgado Ouedraogo University Hospital). 


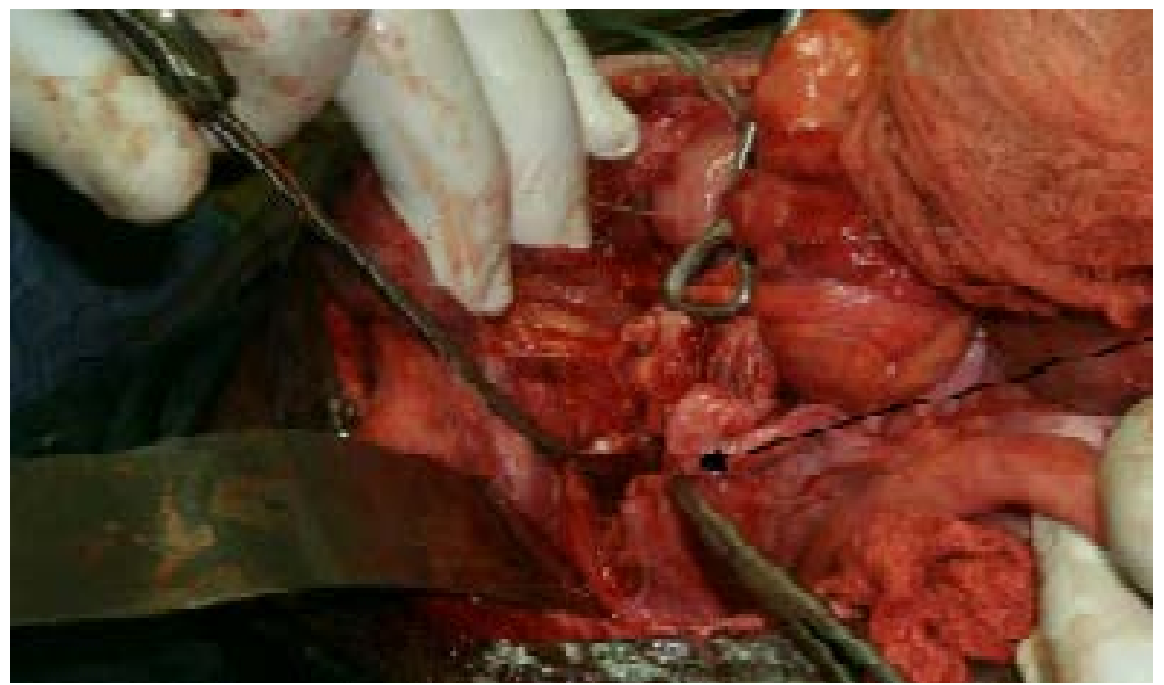

Figure 4. Dissection of the ureter (Urology/Yalgado Ouedraogo University Hospital).

\section{Conclusion}

Urological complications of obstetric and gynaecological surgery are dominated by ligation or resection of the ureter in our context. Caesarian section has been identified as the main aetiological of these lesions. Adequate surgical training and meticulous respect of appropriate operative techniques are essential. Iatrogenic lesions of the ureter most often manifest in the early post-operative period with anuria, and longer-term with urinary leakage or lumbar pain. Management is essentially surgical with satisfactory outcomes.

\section{References}

[1] Liapis, A., Bakas, P., Sykiotis, K., Smyrmiotis, V. and Creatsas, G. (2000) Urinomas as a Complication of Iatrogenic Ureteric Injuries in Gynecological Surgery. European Journal of Obstetrics \& Gynecology and Reproductive Biology, 91, 83-85. https://doi.org/10.1016/S0301-2115(99)00237-7

[2] Sakellariou, P., Protopapas, A.G., Voulgaris, Z., Kyritsis, N., Rodolakis, A., Vlachos, G., et al. (2002) Management of Ureteric Injuries during Gynecological Operations: 10 Years' Experience. European Journal of Obstetrics \& Gynecology and Reproductive Biology, 101, 179-184. https://doi.org/10.1016/S0301-2115(01)00521-8

[3] Karmouni, T., Patard, J., Bensalah, K., Manunta, A., Guillé, F. and Lobel, B. (2001) Prise en charge urologique des traumatismes iatrogènes de l'uretère. Prog Urol, 11, 642-646.

[4] Fröber, R. (2007) Surgical Atlas, Surgical Anatomy of the Ureter. BJU International, 100, 949-965. https://doi.org/10.1111/j.1464-410X.2007.07207.x

[5] Liapis, A., Bakas, P., Giannopoulos, V. and Creatsas, G. (2001) Ureteral Injuries during Gynecological Surgery. International Urogynecology Journal, 12, 391-394. https://doi.org/10.1007/PL00004045

[6] Tijani, K.H., Onwuzurigbo, K.I., Ojewola, R.W., Afolabi, B.B. and Akanmu, N.O. (2011) Iatrogenic Ureteric Injuries in a Nigerian Teaching Hospital: Experience in the Last Decade. East African Medical Journal, 88, 304-309. 
[7] Kamina, P. (2009) Anatomie Clinique Tome IV. Maloine, Paris, 379 p.

[8] Brandes, S., Coburn, M., Armenakas, N. and McAninch, J. (2004) Diagnosis and Management of Ureteric Injury: An Evidence-Based Analysis. BJU International, 94, 277-289. https://doi.org/10.1111/j.1464-410X.2004.04978.x

[9] Diallo, A.B., Sy, T., Diallo, T.M.O., Bah, A.B., Touré, A., Bah, M.D. and Diallo, M.B. (2015) Surgical Treatment of Urological Complications of Gynecological Andobstetric Surgeries at the University Hospital of Conakry Guinea. Open Journal of Urology, 5, 231-237.

[10] Rafique, M. and Hanif, A. (2002) Management of Iatrogenic Urteric Injuries Associated with Gynecological Surgery. International Urology and Nephrology, 1, 31-35. https://doi.org/10.1023/A:1021320409583

[11] Chalya, P., Anthony, N.M., Albert, K. and Samson, S. (2015) Iatrogenic Ureteric Injuries Following Abdominopelvic Operations: A 10-Year Tertiary Care Hospital Experience in Tanzania. World Journal of Emergency Surgery, 10, 17-27. https://doi.org/10.1186/s13017-015-0011-z

[12] Bouya, P.A., Odzébé, A.W., Otiobanda, F.G., Itoua, C. and Mahoungou-Guimbi, K., Banga, M.R. (2011) Les complications urologiques de la chirurgie gynécologique. Prog Urol, 21, 875-878. https://doi.org/10.1016/j.purol.2011.03.008

[13] Traoré, Y. (2011) Traumatismes iatrogènes des uretères en chirurgie gynécologique au CHUYO à propos de 23 cas colligés. Th Med UFR/SDS Université de Ouagadougou, $\mathrm{n}^{\circ} 202,90 \mathrm{p}$.

[14] Hounnasso, P.P., Avakoudjo, J.G., Babadi, N., Paré, A.K., Ouattara, A., Vodounou, A. and Agounkpé, M.M. (2014) Urologic Complications after Gynecologic and Obstetric Surgery at the Urology-Andrology Teaching Clinic of Teaching Hospital of Cotonou. Open Journal of Urology, 4, 10-14.

[15] Benchekroun, A., Lachkara, A., Soumana, A., Farih, M., Belahnech, Z., Marzouk, M. and Faik, M. (1997) Les traumatismes de l'uretère: A propos de 42 cas. Ureteric trauma based. Annale d' urologie, 31, 235-332. 